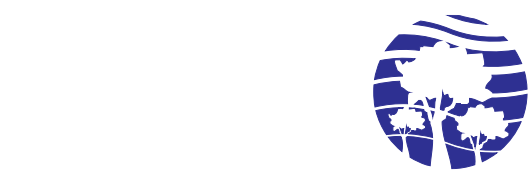

\author{
E N F L O \\ Ecologia e Nutrição Florestal \\ www.enflo.com.br
}

\title{
O uso do software Imagej na estimativa de substrato exposto pós controle de gramíneas invasoras $^{1}$
}

\author{
Leonardo Palhares da Silveira ${ }^{2}$; Eduarda Soares Menezes ${ }^{3}$; Danielle Piuzana Mucida ${ }^{4}$; Israel \\ Marinho Pereira ${ }^{5}$; José Barbosa dos Santos ${ }^{6}$; Marcio Leles Romarco de Oliveira ${ }^{7}$
}

\begin{abstract}
Resumo: Espécies de gramíneas (Poaceae) têm sido recomendadas em processos iniciais de recuperação. Entretanto, necessitam de um controle posterior, para evitar competição com espécies de interesse, especialmente arbóreas. Neste contexto, objetivou-se, por meio do software ImageJ, quantificar o substrato exposto em uma área degradada em Diamantina, MG, sobre a qual foram aplicados distintos métodos de capina para o controle das gramíneas exóticas Urochloa decumbes (Stapf) RD, Wabster e Melinis minutiflora P. Beauv.. Foi realizado o controle das gramíneas por meio da aplicação de diferentes métodos (químico, manual e mecânico), distribuídos em 4 blocos, subdivididos em parcelas e subparcelas. Após 100 dias, por meio de imagens processadas pelo ImajeJ, observou-se que método químico proporcionou a menor exposição do substrato e maior presença de biomassa superficial, diferentemente do método manual, onde houve menor cobertura vegetal. Foi possível quantificar o substrato exposto em ambiente com controle de gramíneas permitindo, de modo eficaz, o planejamento das técnicas de recuperação. $\mathrm{O}$ uso do ImageJ se mostrou eficiente, representando uma alternativa para a quantificação de substrato, e diversos estudos inerentes à análise de cobertura vegetal de ambientes degradados.
\end{abstract}

Palavras - chave: Área degradada; Melinis minutiflora; Urochloa decumbes.

\section{The use of the Imagej software in the estimation of exposed substrate after control of invasive grasses}

\begin{abstract}
Species of the grass (Poaceae) have been recommended in initial recovery processes. However, they need a posterior control, avoiding the competition with those of interest, especially arboreal ones In this context, the objective was to quantify the exposed substrate in a degraded area in Diamantina, Minas Gerais, by of ImageJ software, on which different methods of weeding were applied for the control of exotic grasses Urochloa decumbes (Stapf) RD, Wabster and Melinis minutiflora P. Beauv. Control of grasses was carried out by applying different methods (chemical, manual and mechanical), distributed in 4 blocks, subdivided into plots and subplots. After 100 days, by means of ImajeJ processing images, it was observed that chemical method provided the lowest exposure of the substrate with greater presence of superficial biomass, unlike the manual method, which showed less vegetation cover. It was possible to quantify the substrate exposed in an environment with grass control, allowing effective planning of recovery techniques. The use of ImageJ was efficient, representing an alternative for the substrate quantification and several studies inherent in the analysis of vegetation coverage of degraded environments.
\end{abstract}

Keywords: Degraded area; Melinis minutiflora; Urochloa decumbes.

\footnotetext{
${ }^{1}$ Recebido em 05.07.2018 e aceito para publicação como artigo científico em 19.10.2018.

${ }^{2}$ Engenheiro Florestal, Mestre em Ciência Florestal, Doutorando em Ciência Florestal, Universidade Federal dos Vales do Jequitinhonha e Mucuri, Diamantina, Minas Gerais, Brasil. E-mail: <leopalhares.cc@ hotmail.com>

${ }^{3}$ Engenheira Florestal, Mestranda em Ciência Florestal, Universidade Federal dos Vales do Jequitinhonha e Mucuri. E-mail: <eduarda_menezs@hotmail.com>

${ }^{4}$ Geóloga, Pós-Doutora em Geologia, Professora Associada, Programa de Pós-Graduação em Ciência Florestal, Universidade Federal dos Vales do Jequitinhonha e Mucuri. E-mail: <dpiuzana @ yahoo.com.br>

${ }^{5}$ Engenheiro Florestal, Pós-Doutor em Engenharia Florestal, Professor Associado, Programa de Pós-Graduação em Ciência Florestal, Universidade Federal dos Vales do Jequitinhonha e Mucuri. E-mail: <imarinhopereira@gmail.com>

${ }^{6}$ Engenheiro Agrônomo, Pós-Doutor em Produção Vegetal. Professor Associado, Programa de Pós-Graduação em Ciência Florestal, Universidade Federal dos Vales do Jequitinhonha e Mucuri. E-mail: <jbarbosasantos@ yahoo.com.br>

${ }^{7}$ Engenheiro Florestal, Doutor em Ciência Florestal. Professor Associado, Programa de Pós-Graduação em Ciência Florestal, Universidade Federal dos Vales do Jequitinhonha e Mucuri. E-mail: <marcioromarco@gmail.com>
} 


\section{Introdução}

As recentes preocupações com a crescente perda da biodiversidade nos ecossistemas, devido aos processos antrópicos, têm gerado cuidados e necessidades quanto a utilização de medidas mitigadoras (ALMEIDA et al., 2011). O potencial de algumas gramíneas é destacado na recuperação de áreas degradadas, pelo fato de que várias espécies apresentam características morfológicas e fisiológicas que lhes permitem sobreviver em ambientes hostis, tornando-as boas candidatas à reabilitação de terras (JACOBI et al., 2008; FILGUEIRAS; FAGG, 2008). Muitas espécies possuem alto índice de valor de importância em algumas pastagens, desenvolvendo-se em afloramentos rochosos (quartzitos), onde características do solo e condições microclimáticas podem ter condicionado às adaptações que tornaram tais plantas potenciais à aplicação na recuperação de áreas degradadas (FIGUEIREDO et al., 2012).

Espécies da família Poaceae predominam em formações campestres, sendo menos comuns no interior das estruturas florestais. A importância ecológica e econômica desta família é indiscutível, pela dominância em vários ecossistemas vegetais. Entretanto, algumas espécies possuem elevada habilidade competitiva, sobrevivendo e se reproduzindo nas mais diversas condições de estresse ambiental, garantindo fácil disseminação (BRIGHENTI, 2001).

A agressividade promovida pelas características de gramíneas, como as do gênero Urochloa, requerem medidas de intervenção no sentido de permitir o desenvolvimento de outras espécies, tais como as arbóreas, em ambientes a serem recuperados. $\mathrm{Na}$ recuperação de áreas degradadas, a presença de plantas invasoras é considerada um dos principais problemas, especialmente no início do processo de regeneração natural ou artificial, onde pode ocorrer intensa competição entre espécies (YAMASHITA et al., 2017). A análise da exposição do substrato é empregada em processos de planejamento e tomadas de decisão, para implantação de um plano de recuperação de uma área. Estudos de susceptibilidade à perda de solo são importantes para identificação de áreas vulneráveis à erosão, assim como competição entre plantas daninhas e espécies presentes em determinado local (PINTO et al., 2015).

Estimativas do percentual de substrato exposto podem ser obtidas por diferentes ferramentas, como por exemplo, a utilização de softwares especializados para o emprego de análise de imagens, que constituem importantes ferramentas auxiliares (DIAS, 2008). O Image

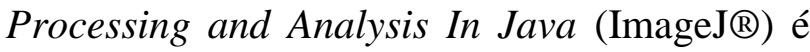
um software livre, usado para tratamento e processamento de imagens, constituindo uma ferramenta rápida e eficiente para estimar exposição de substrato e/ou solo, por meio de quantificação de variáveis, aplicação de tratamentos para $\mathrm{o}$ processamento $\mathrm{e}$ interpretação dos resultados (PASSONI et al., 2014). Pelo ImageJ é possível editar, exibir e analisar em inúmeros formatos (extensões), e o software tem apresentado resultados satisfatórios em diversos tipos de análises do solo e vegetação em ambientes degradados (LAURENCE; CHROMY, 2010). A eficácia das análises tem demostrado que o ImageJ pode ser inserido em diversas áreas científicas, promovendo novas técnicas e produção de conteúdo (SCHNEIDER et al., 2012).

Neste contexto, objetivou-se, por meio do software ImageJ, quantificar o substrato exposto em uma área degradada em Diamantina, MG, sobre a qual foram aplicados distintos métodos de capina para o controle de gramíneas exóticas Urochloa decumbes e Melinis minutiflora.

\section{Material e métodos}

O estudo foi desenvolvido no período de julho de 2015 a março de 2016, em uma área com cerca de 1,0 ha, localizada nas coordenadas $18^{\circ} 12^{\prime} 18.85^{\prime \prime S}$ de latitude Sul e $43^{\circ} 34^{\prime} 9.12^{\prime \prime O}$ de longitude Oeste. A área se localiza no Campus Universitário Juscelino Kubitscheck da Universidade Federal dos Vales do Jequitinhonha e Mucuri (Figura 1), na mesorregião do Alto Jequitinhonha, porção 
Sudeste do município de Diamantina, Minas

Gerais.

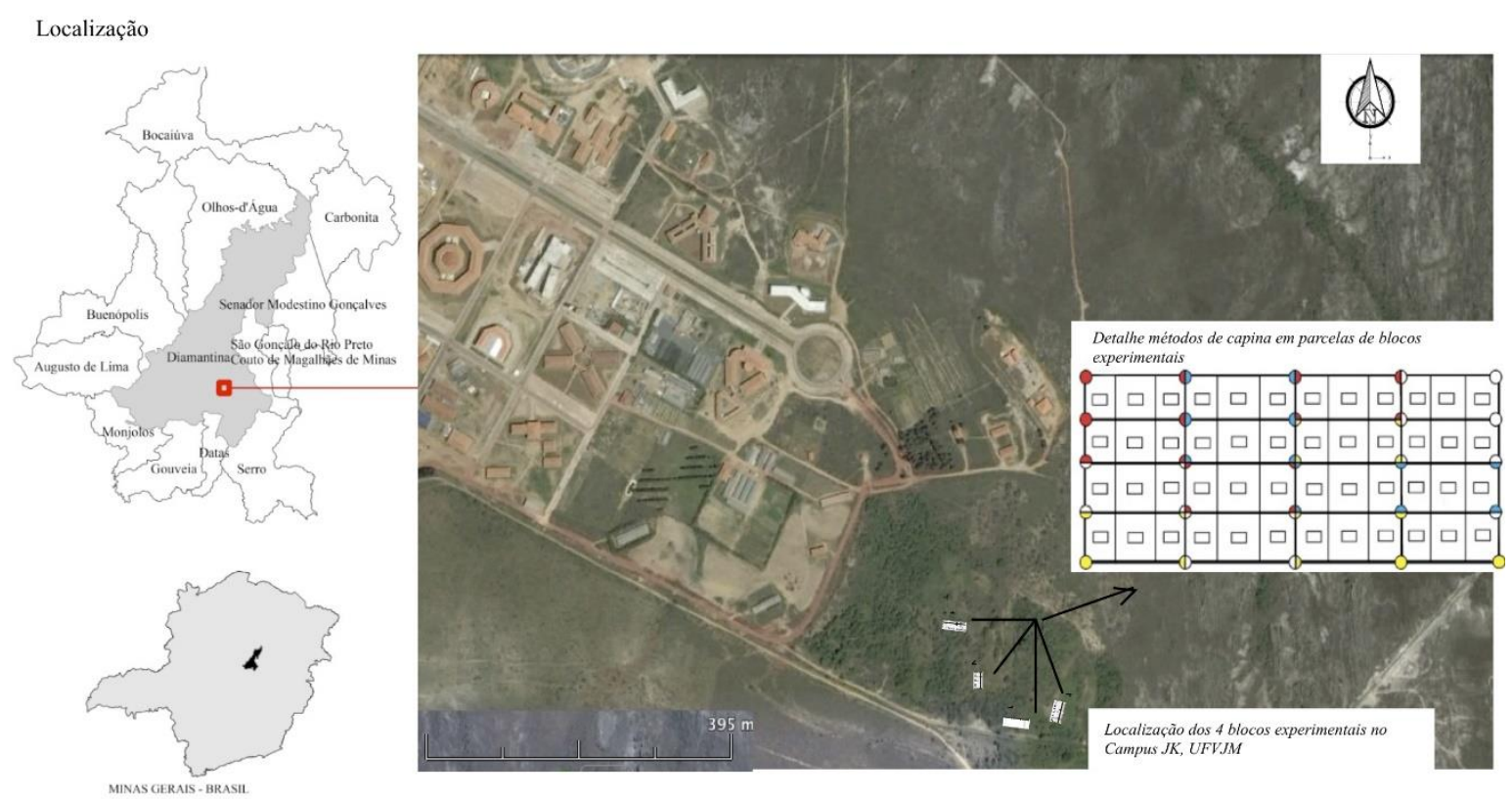

Figura 1 - a) Localização de Diamantina no contexto de Minas Gerais, no contexto municipal e Campus JK, UFVJM, com demarcação das áreas experimentais. Fonte: Google Satélite, IBGE - Datum SIRGAS 2000, UTM 23S.

Figure 1 - Location of Diamantina in Minas Gerais state, in the municipal context and JK Campus, Federal UFVJM, with demarcation of the experimental areas. Source: Google Satellite, IBGE - Datum SIRGAS 2000, UTM 23S.

O clima é classificado como $\mathrm{Cwb}$, de acordo com o sistema de classificação climática Köppen-Geiger (ALVARES et al., 2013), e exibe duas estações distintas: uma estação chuvosa que ocorre entre outubro e março e uma estação seca, que ocorre entre abril e setembro. A temperatura média anual é de $19^{\circ} \mathrm{C}$ e a precipitação anual é de aproximadamente 1.400 mm (VIEIRA et al., 2010), com uma altitude média de $1.296 \mathrm{~m}$.

A área que abarca o estudo serviu como aterro controlado da sede municipal de Diamantina, Minas Gerais, sendo desativado em 2002. Posteriormente, houve a preocupação para a recomposição da vegetação e cobertura de possíveis focos de erosão, provenientes da exposição do substrato. Foram introduzidas mudas de espécies arbóreas ao acaso, na tentativa de formar núcleos de vegetação, assim como espécies de gramíneas exóticas como Urochloa decumbes e Melinis minutiflora com o intuito de promover uma rápida cobertura do substrato (MACHADO et al., 2012).

Foram implantados 4 blocos experimentais em agosto de 2015. Cada bloco foi subdividido em 16 parcelas de $4 \mathrm{~m} \times 10 \mathrm{~m}\left(40 \mathrm{~m}^{2}\right)$, nas quais foram definidas 3 áreas de 1,0 $\mathrm{m} 2$, totalizando em 48 sub-parcelas, com a ajuda de moldura em ferro de dimensões $0,05 \mathrm{~m}$ x $1,0 \mathrm{~m} \times 1,0 \mathrm{~m}$ (Figura 2). Os blocos experimentais caracterizam-se pela predominância de gramíneas e nas adjacências alguns núcleos de vegetação, com presença de espécies arbóreas ruderais tais como Psidium guajava L., Ricinus communis L., Vernonia polysphaera Baker, além de espécies nativas como Eremanthus incanus (Less.) Less, Dalbergia miscolobium Benth; Stryphnodendron adstringens (Mart.) Coville, Hymenaea stigonocarpa Mart. ex Hayne e Tabebuia ochracea (Cham.) Standl.

Para o estudo de substrato exposto pós controle de gramíneas exóticas $U$. decumbes e M. minutiflora, por meio do software Image $\mathrm{J}$, aplicaram-se quatro métodos de controle em 
parcelas de cada bloco: (i) químico, que contou com aplicação do herbicida glyphosate (36\%), na dosagem recomendada de 4,0 1/ha; (ii) manual, por meio do uso de enxada e rastelo, deixando o substrato exposto; (iii) mecânico, por uso de roçadeira e (iv) tratamento duplo (mecânico + químico).

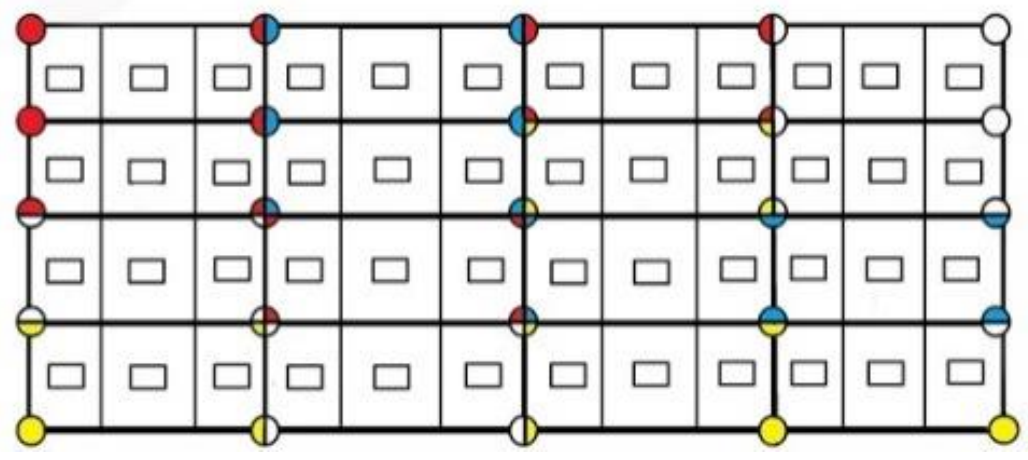

Figura 2 - Detalhamento de um bloco experimental nos quais foram aplicados métodos de controle manual (azul), vermelho (mecânico), químico (branco) e químico + mecânico (amarelo).

Figure 2 - Detail of one experimental block in which manual (blue), red (mechanical), chemical (white) and chemical + mechanical (yellow) control methods were applied.

Após 100 dias de aplicação dos métodos de controle, em dezembro de 2015 , foram obtidas as imagens para o uso no software ImageJ. Para cada parcela foram tomadas 3 imagens digitais, totalizando em 192 imagens referentes aos 4 blocos experimentais. Foram registradas sob iluminação solar, a uma altura de 1 metro da superfície, com uso de câmera digital Samsung, com 13.0 megapixels. Posteriormente foram transferidas para o computador e analisadas pelo software Image J@ versão 1.49 , de linguagem Java, disponível no site http://rsbweb.nih.gov/ij.
Foram executados procedimentos para que a imagem mantivesse a escala adequada, com o intuito de diminuir as incertezas e aumentar a precisão dos dados obtidos. Determinaram-se estimativas de percentagem de área total ocupada pelas gramíneas (em branco) e o substrato exposto (em preto). As imagens processadas foram salvas no formato TIFF ( Tag Image File Format), ambiente usado no processo de binarização e análise das imagens (Figura 3).

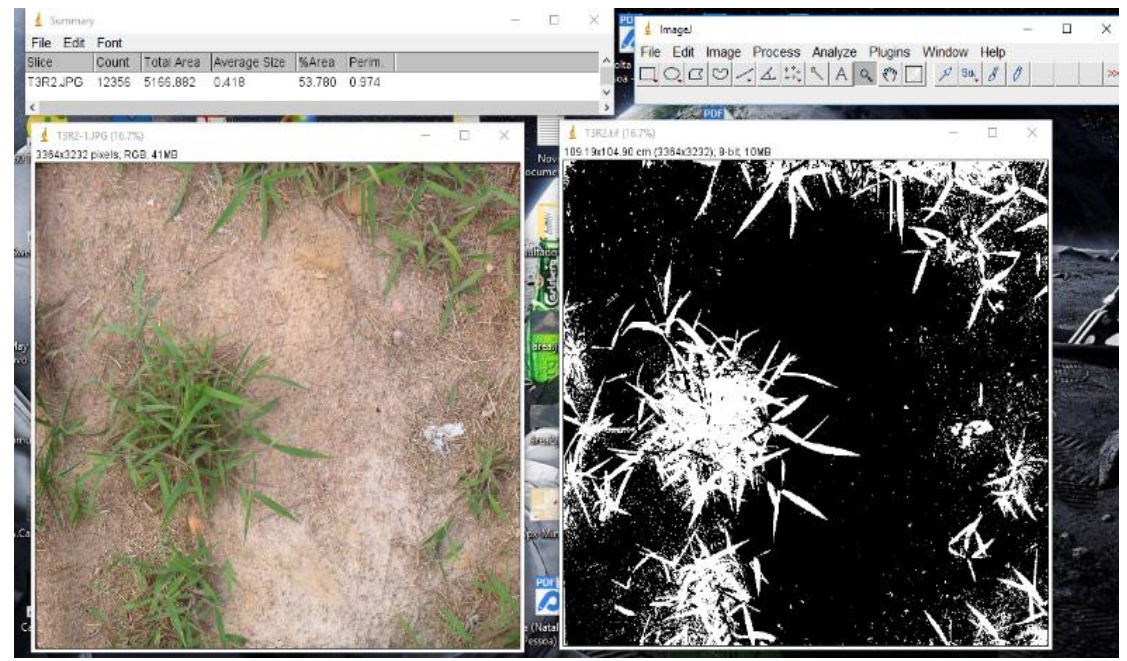

Figura 3. Interface do software ImageJ para a estimativa de área de substrato exposto.

Figure 3. ImageJ software interface for the estimation of exposed substrate area. 
Os valores encontrados de percentagem de substrato exposto pelo ImageJ nas parcelas dos 4 blocos foram submetidos à análise de variância. Para a separação dos contrastes de médias, após a análise de variância dos dados (ANOVA), utilizou-se o teste de Tukey com significância de 5\%. As análises estatísticas foram realizadas com o auxílio do software R(C Versão 3.2.3 (R CORE TEAM, 2015).

\section{Resultados e Discussão}

A Tabela 1 apresenta os dados em percentual de substrato exposto obtidos nas imagens tratadas no software ImageJ, assim como a média por método e a média total. A Figura 4 apresenta as médias de estimativa da percentagem do substrato exposto, nos diferentes métodos de capina. A média geral de substrato exposto, obtida a partir das análises das imagens pelo ImageJ, foi de $27,66 \%$ (Tabela 1) e os resultados variaram de $0,01 \%$ a $95,88 \%$.

A análise a partir do software ImageJ, para o método manual, apresentou a maior percentagem de substrato exposto (Figura 5a, b), com média de 77,50\%. Pode-se afirmar que esse método de controle proporcionou maior exposição do substrato às intempéries, quando comparado à análise de imagens de sub parcelas onde foram aplicados os demais métodos de capina.

Tabela 1 - Médias do substrato exposto obtidas pelo software ImageJ aos 100 dias após a aplicação dos métodos de controle. Table 1 - Exposed substrate averages obtained by ImageJ software 100 days after control methods.

\begin{tabular}{|c|c|c|c|c|c|}
\hline \multirow{2}{*}{ MÉTODOS } & BLOCO 1 & BLOCO 2 & BLOCO 3 & BLOCO 4 & \multirow{2}{*}{ MÉDIA } \\
\hline & \multicolumn{4}{|c|}{$(\%)$} & \\
\hline \multirow{4}{*}{ Manual } & 86,01 & 93,49 & 68,96 & 92,64 & \multirow{4}{*}{77,50} \\
\hline & 76,31 & 84,33 & 91,25 & 52,92 & \\
\hline & 74,54 & 79,5 & 61,35 & 80,32 & \\
\hline & 71,59 & 87,55 & 69,63 & 69,6 & \\
\hline \multirow{4}{*}{ Mecânico } & 0,73 & 0,78 & 23,09 & 0,72 & \multirow{4}{*}{14,96} \\
\hline & 0,46 & 13,11 & 56,28 & 2,65 & \\
\hline & 0,09 & 38,32 & 49 & 11,64 & \\
\hline & 4,46 & 10,57 & 8,65 & 18,77 & \\
\hline \multirow{4}{*}{ Químico } & 2,79 & 4,09 & 1,68 & 0,85 & \multirow{4}{*}{7,45} \\
\hline & 1,23 & 24,32 & 6,76 & 0,68 & \\
\hline & 5,74 & 1,63 & 22,25 & 16,53 & \\
\hline & 13,6 & 5,82 & 10,07 & 1,22 & \\
\hline \multirow{4}{*}{ Químico + Mecânico } & 0,95 & 19,7 & 2,28 & 1,23 & \multirow{4}{*}{10,71} \\
\hline & 2,99 & 62,16 & 6,55 & 4,3 & \\
\hline & 1,87 & 5 & 9,54 & 10,79 & \\
\hline & 12,45 & 3,56 & 12,31 & 15,74 & \\
\hline MÉDIA TOTAL & & & & & 27,66 \\
\hline
\end{tabular}




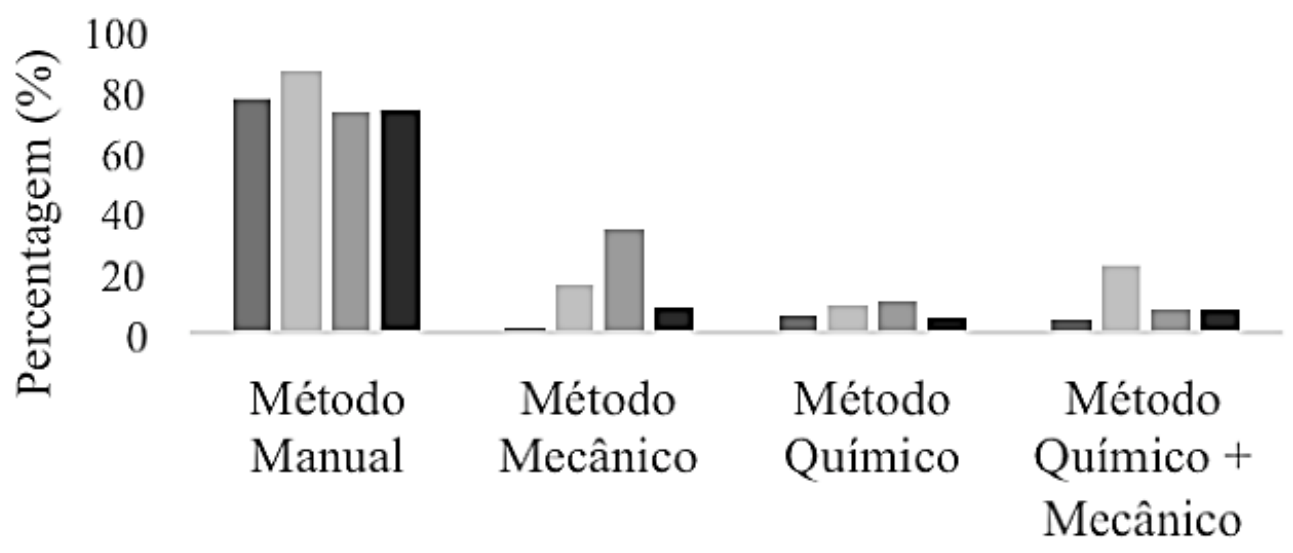

\section{abloco 1 $\square$ Bloco 2 $\square$ Bloco3 $\quad$ Bloco 4}

Figura 4 - Percentagem de solo exposto aos 100 dias após o controle de U. decumbes e M. minutiflora obtidos pelo software ImageJ.

Figure 4 - Percentage of soil exposed after 100 days post control of $U$. decumbes and M. minutiflora obtained by ImageJ software.

Imagens processadas em área onde foi aplicado o método mecânico (Figura 5c, d), após os 100 dias, apresentou média de 14,96\% de substrato exposto. Já as imagens analisadas de áreas de capina química (Figuras 5e, f) e química + mecânica (Figuras 5g, h), mostraram os menores percentuais de exposição de substrato, com $7,45 \%$ e $10,71 \%$, respectivamente.

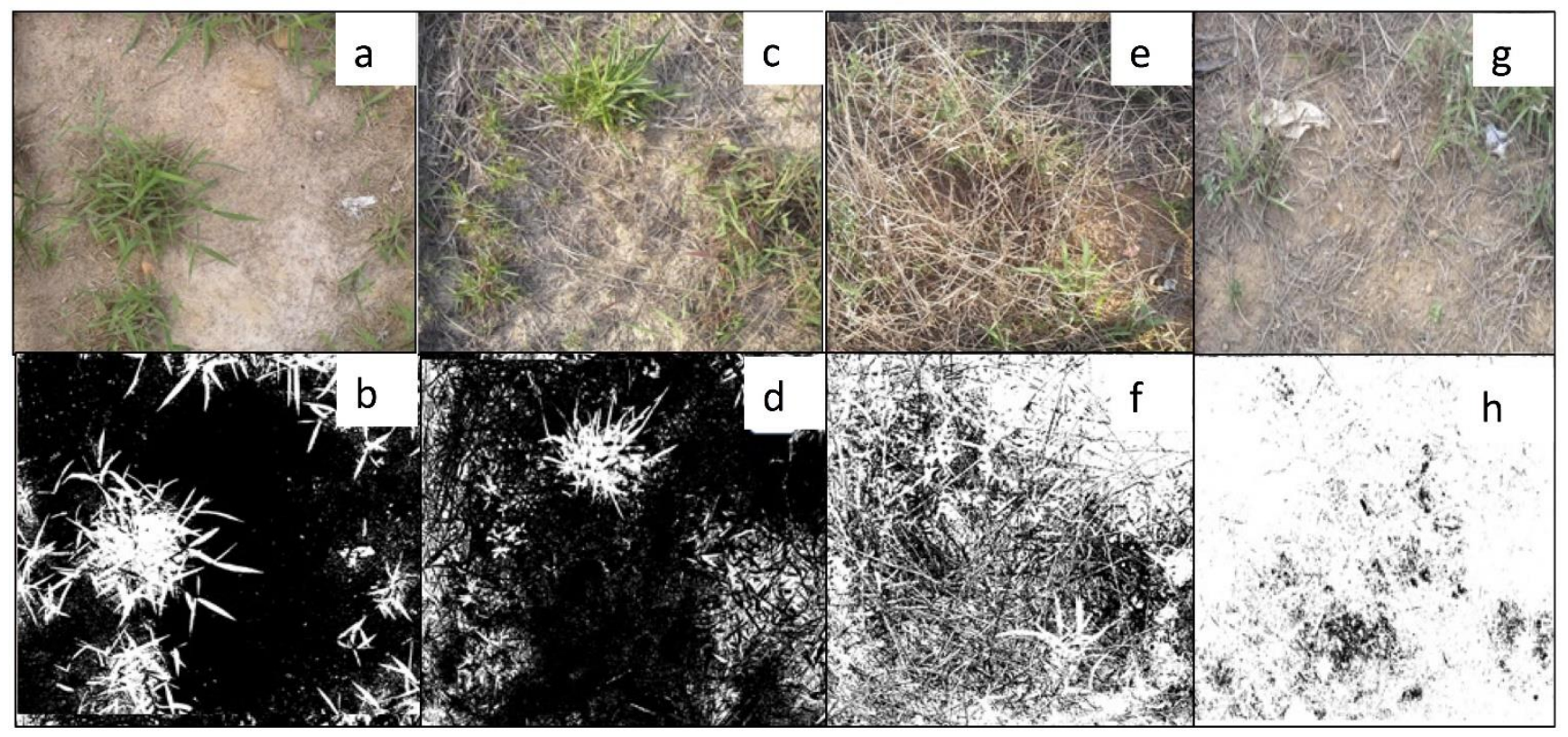

Figura 5 - Imagens obtidas e processadas no software ImageJ aos 100 dias após o controle de $U$. decumbes e M. minutiflora pelo método manual $(\mathrm{a}, \mathrm{b})$; método mecânico $(\mathrm{c}, \mathrm{d})$; método químico $(\mathrm{e}, \mathrm{f})$ e método mecânico + químico $(\mathrm{g}$, h) respectivamente.

Figure 5 - Images obtained and processed in the ImageJ software after 100 days of the control by manual method (a,b); mechanical method $(\mathrm{c}, \mathrm{d})$; chemical method $(\mathrm{e}, \mathrm{f})$ and mechanical + chemical method $(\mathrm{g}, \mathrm{h})$ respectively. 
Sabe-se que a presença de vegetação produz biomassa, favorecendo o aumento de matéria orgânica e a estabilidade do terreno, evitando que nutrientes presentes sejam removidos. Nesse sentido, as gramíneas também podem ser eficientes para contribuir ao aumento na concentração de nutrientes em áreas degradadas (DASS et al., 2011).

A percentagem média de exposição do substrato indicou a influência dos métodos de capina sobre a cobertura vegetal. Entretanto, a ausência de cobertura vegetal impacta o ambiente, uma vez que, a chuva não é interceptada antes de atingir a superfície do solo, levando, normalmente, a uma maior desagregação das partículas do substrato. Este processo, somado às questões vinculadas à topografia, pode ocasionar enxurradas cuja velocidade pode ser suficiente para carrear partículas da superfície do substrato e/ou solo (LIMA et al., 2013).

$\mathrm{Na}$ análise de variância dos dados, os valores encontrados apontam para uma diferença significativa entre a percentagem de substrato exposto no período estudado (Tabela 2).

Tabela 2 - Análise de variância dos dados de percentagem de cobertura.

Table 2 - Data analysis of variance of the percentage of coverage variable data.

\begin{tabular}{ccc}
\hline FV & GL & Quadrados médios \\
\hline Tratamento & & Cobertura $(\%)$ \\
Bloco & 3 & $13362,6^{*}$ \\
Resíduo & 3 & 358,8 \\
CV $(\%)$ & 9 & 565,8 \\
\hline
\end{tabular}

FV: Fonte de Variação; GL: Graus de Liberdade; CV: Coeficiente de Variação;

* Diferença significativa a $5 \%$ de probabilidade de erro.

No teste de comparação de médias, observouse que o método com maior média de percentagem de substrato exposto foi o manual, com valor de $77,49 \%$, diferindo do encontrado para as áreas com aplicação dos demais métodos de capina. O valor encontrado para as áreas com método químico foi o que apresentou a menor média, de 7,45\%, seguido da combinação do método químico + mecânico, com $10,71 \%$ de cobertura (Tabela 3).

Tabela 3 - Comparativo de médias entre os diferentes métodos de capina para o controle de U. decumbes e M. minutiflora Table 3 - Means comparison between different weeding methods for the control of $U$. decumbes and M. minutiflora

Métodos de controle

*Médias seguidas por mesma letra, não diferem entre si pelo teste de Tukey, a 5\% de significância.

\begin{tabular}{cc}
\hline Método Manual & $77,49 \mathrm{a}$ \\
Método Mecânico & $14,95 \mathrm{~b}$ \\
Método Químico & $7,45 \mathrm{~b}$ \\
Método Químico + Mecânico & $10,71 \mathrm{~b}$ \\
\hline
\end{tabular}

Média dos tratamentos * 
É possível observar, por meio das imagens, que o método manual proporcionou uma maior exposição do substrato às intempéries. Isso pode favorecer o surgimento dos problemas relacionados aos processos erosivos, que podem ocasionar a perda de solo e nutrientes (PINESE JÚNIOR et al., 2008). Schaefer et al. (2002), em estudo sobre as perdas de solo sob chuva simulada, verificaram que em terrenos com percentagem de cobertura vegetal variando entre 0 e 40\%, as perdas totais de solo foram superiores a $11 \mathrm{t} \mathrm{ha}^{-1}$, por outro lado, em áreas com cobertura de $80 \%$ houve diminuição da perda de material para cerca de $5 \mathrm{t} \mathrm{ha}^{-1}$.

As análises de imagens pelo ImageJ para áreas nas quais foram aplicadas o método químico, apresentaram uma menor exposição do substrato e uma elevada quantidade de biomassa superficial, conferindo proteção. Em estudo semelhante, Silveira et al. (2018) utilizaram a mesma metodologia e constataram que, a capina química proporciona uma maior percentagem de cobertura do substrato, devido a quantidade de biomassa seca resultante da aplicação do herbicida. A eficiência desse método também foi demonstrada por Machado et al. (2012), em área próxima à desta pesquisa, no qual o uso de glyphosate levou à diminuição de germinação de espécies exóticas, onde a ação sistêmica associada ao baixo custo, favorece a aplicação desse herbicida para o controle de gramíneas em área para recuperação (SANTOS et al., 2007).

Em relação aos outros métodos utilizados no presente estudo (Mecânico e Mecânico + Químico), os dados processados pelo software ImageJ indicam que substrato não foi totalmente exposto. A cobertura vegetal (material seco oriundo das gramíneas cortadas e dessecadas) atuou na cobertura do substrato contra os processos erosivos e perda de material particulado, garantindo proteção direta e indireta contra o escoamento superficial, favorecendo a infiltração e interceptação das chuvas.

No entanto, a resposta de cada método de controle nesse experimento gera quantidades variadas de biomassa, assim como observado no estudo realizado por Silveira et al. (2018). Tais métodos, quando não planejados ou executados de maneira inadequada, contribuem fortemente com desequilíbrio do ecossistema, favorecendo ou prejudicando a absorção da radiação necessária para fotossíntese (OLIVEIRA et al., 2017).

A área em questão apresenta uma elevada vulnerabilidade ambiental, dificultando todos os processos de recuperação. Por se tratar de um antigo aterro controlado, dificuldades relacionam-se à heterogeneidade do substrato, devido aos diferentes tipos de materiais depositados. Neste sentido, estudos que possibilitem o levantamento da cobertura e exposição de substrato podem auxiliar, sobremaneira, no planejamento e tomada de decisão dos melhores métodos e técnicas a serem utilizados.

Um fator que pode contribuir para diminuição dos processos de regeneração natural é a presença desordenada das gramíneas, pois há inibição da chegada e desenvolvimento de espécies nativas no local. Machado et al. (2012) verificaram um baixo número de espécies arbóreas e arbustivas regenerantes em locais com incidência de gramíneas superior a 75\%, na mesma área do presente estudo. Entretanto, quando há índices inferiores a 50\%, verificou-se um aumento na representatividade de indivíduos regenerantes de espécies nativas. Neste sentido, observa-se que as gramíneas inibem a regeneração natural nas situações analisadas.

A realização de estudos dessa natureza é desejável, de modo a subsidiar dados para elaboração de planejamentos sustentáveis e diagnósticos da cobertura do substrato, em ambientes degradados. Além disso, podem contribuir para a conservação, assim como na observação do comportamento das gramíneas e plantas espontâneas sob o efeito dos métodos utilizados.

\section{Conclusões}

O processamento de imagens pelo software ImageJ indicou que, nas áreas onde foi adotado o método químico de controle, houve menor exposição do substrato e uma maior presença de biomassa superficial. Esse foi seguido pelo 
método químico + mecânico e, posteriormente, pelo mecânico. O estudo demonstrou a diferença significativa nas análises de imagens do método manual, as quais apresentaram menor cobertura vegetal, ou seja, maior exposição do substrato, após os 100 dias. O software ImageJ mostrouse uma ferramenta de fácil utilização, custo e eficaz na mensuração da exposição e presença do substrato exposto, constituindo uma ferramenta válida para aplicação em diversas áreas degradadas e situações ambientais.

\section{Agradecimentos}

Os autores agradecem aos avaliadores anônimos e ESM e LPS à CAPES, por concessão de bolsa que viabilizou este estudo.

\section{Referências}

ALMEIDA, F. S.; GOMES, D. S.; QUEIROZ, J. M. Estratégias para a conservação da diversidade biológica em florestas fragmentadas. Ambiência, v. 7, n. 2, p. 367-382, 2011.

ALVARES, C.A. et al. Köppen's climate classification map for Brazil. Meteorologische Zeitschrift, v. 22, n. 6, p. 711-728, 2013. Disponível em: <https://www.schweizerbart.de/.../Koppen_s_cl imate_classification...>. Acesso em: 12 jun. 2018.

BRIGHENTI, A. M. Biologia de plantas daninhas. In: OLIVEIRA JR, R. S.; CONSTANTIN, J. Plantas Daninhas e seu manejo. Guaíba: Agropecuária, p. 103-121, 2001.

DASS, A. et al. Runoff capture through vegetative barriers and planting methodologies to reduce erosion, and improve soil moisture, fertility and crop productivity in southern Orissa, India. Nutrient Cycling Agroecosystems, v. 89, n.1, p. 45-57, 2011. DOI: https://doi.org/10.1007/s10705-010-9375-3.

DIAS, F. C. Uso do software Image $\mathbf{J}$ para análise quantitativa de imagens de microestruturas de materiais. Dissertação de mestrado, INPE, 148p, 2008. Disponível em: <http://urlib. net/sid. inpe. br/mct-m17@ 80/2008/04.30>. Acesso em: 12 jun. 2018.

FIGUEIREDO, M. A.; BAÊTA, H. E.; KOZOVITS, A. R. Germinação de gramíneas nativas com potencial aplicação na recuperação de áreas degradadas no Quadrilátero Ferrífero, Brasil. Neotropica, v. 12, n. 3, Campinas, SP, 2012.

DOI:10.1590/S167606032012000300013.

FILGUEIRAS, T. S.; FAGG, C. W. Gramíneas nativas para uma recuperação de áreas degradadas no cerrado. In: Bases para uma recuperação de áreas degradadas na Bacia do São Francisco In: FELFILI, J. M.; SAMPAIO, J. C; CORREIA, CRM de A. (eds). Bases para a recuperação de áreas degradadas na Bacia do São Francisco, Brasília: Editora UnB, 2008, p.89-108.

JACOBI, C.M.; CARMO, F.F.; VINCENT, R.C. Estudo fitossociológico de uma comunidade vegetal sobre a canga como subsídio para a reabilitação de áreas mineradas no Quadrilátero Ferrífero, MG. Revista Árvore, v. $32, \quad$ n. 2, p. $345-353,2008$. DOI: 10.1590/S0100-67622008000200017.

LAURENCE, T. A.; CHROMY, B. A. Efficient maximum likelihood estimator fitting of histograms. Nature Methods, v. 7, n. 5, p. 338339, 2010. Disponível em: $<$ https://www.nature.com/articles/nmeth0510338>. Acesso em: 10 jun. 2018.

LIMA, G.C. et al., Avaliação da cobertura vegetal pelo índice de vegetação por diferença normalizada (IVDN). Revista Ambiente \& Água, v. 8, n.2, 2013. DOI: http://dx.doi.org/10.4136/ambi-agua.959. 
MACHADO, V. M. et al. Controle químico e mecânico de plantas daninhas em áreas em recuperação. Revista Brasileira de Herbicidas, v. 11, n. 2, p. 139-147, 2012. DOI: http://dx.doi.org/10.4215/rm2017.e16017.

OLIVEIRA, R. C.; BOIN, M. N.; FELICIO, M. $\mathrm{J}$. Teoria da paisagem aplicada à escolha de área para aterros sanitários. Mercator, Fortaleza, v. 16, 2017. DOI: 10.4215/rm2017.e16017.

PASSONI, S. et al. Software Image J to study soil pore distribution. Revista Ciência e Agrotecnologia, Lavras, v.38, n.2, p. 122-128, 2014. DOI: http://dx.doi.org/10.1590/S141370542014000200003.

PINESE JÚNIOR, J. F.; CRUZ L. M.; RODRIGUES, S. C. Monitoramento de erosão laminar em diferentes usos da terra, UberlândiaMG. Sociedade \& Natureza, v.20, n. 2, pp.157175,2008 .

PINTO, C. T. et al. 2015. Identificação de áreas susceptíveis aos processos erosivos na região do Vale do Paraíba. In: SIMPÓSIO BRASILEIRO DE SENSORIAMENTO REMOTO - SBSR, XVII. João Pessoa-PB. Anais... Paraíba: INPE. $2015 . \quad$ Disponível em: <http://www.dsr.inpe.br/sbsr2015/files/p0021.p df $>$. Acesso em: 10 jun. 2018.

R CORE TEAM. R. A language and environment for statistical computing. Vienna: $\mathrm{R}$ Foundation for Statistical Computing, 2015. Disponível em: <http://www.R-project.org/>. Acesso em: 08 ago. 2017.

SANTOS, M. V. et al. Controle de Brachiaria brizantha, com uso do glyphosate, na formação de pastagem de Tifton 85 (Cynodon spp.). Planta Daninha, v.25, n.1, p.149-155, 2007. DOI: http://dx.doi.org/10.1590/S010083582007000100016.

SCHAEFER, C. E. R. et al. Perdas de solo, nutrientes, matéria orgânica e efeitos microestruturais em Argissolo Vermelho-
Amarelo sob chuva simulada. Revista Pesquisa Agropecuária Brasileira, v. 37, n. 5, p. 669-678, 2002. DOI: http://dx.doi.org/10.1590/S0100204X2002000500012.

SCHNEIDER, C. A.; RASBAND, W. S.; ELICEIRI, K. W. N. I. H. Image to ImageJ: 25 years of image analysis. Nature methods, v. 9, n. 7, p. 671, 2012. Disponível em: <https://www.ncbi.nlm.nih.gov/pubmed/22930 834>. Acesso em: 06 jun. 2018.

SILVEIRA, L. P. et al. Evaluation of different methods to control invasive alien grass weeds in a degraded area. African Journal of Agricultural Research, v. 13, n. 32, p. 1655-1660, 2018. DOI: 10.5897/AJAR2018.13276

VIEIRA, J. P. G. et al. Precisão da mensuração durante a estação chuvosa em Diamantina, Minas Gerais. Revista Brasileira de Engenharia Agrícola e Ambiental, n. 14, p. 762-767, 2010. Disponível em: <http://www.scielo.br/pdf/rbeaa/v14n7/a12v14 n7.pdf>. Acesso em: 08 jul. 2018.

YAMASHITA, O. M. et al. Interferência de subdoses de glyphosate no desenvolvimento de plantas jovens de nim. Nativa, Sinop, MT, v.5, n.3, p.163-168, 2017. DOI: 10.5935/23187670.v05n03a02. 